\title{
DESAIN DAN ANALISIS KEKUATAN DUDUKAN (BRACKET) AC OUTDOOR MENGGUNAKAN METODE ELEMEN HINGGA
}

\author{
Lasinta Ari Nendra Wibawa \\ Balai Uji Teknologi dan Pengamatan Antariksa dan Atmosfer \\ Lembaga Penerbangan dan Antariksa Nasional (LAPAN) \\ Email: lasinta.ari@lapan.go.id
}

\begin{abstract}
ABSTRAK
Penelitian ini mengkaji tentang perancangan dan analisis kekuatan dudukan AC outdoor menggunakan metode elemen hingga. Analisis dilakukan menggunakan software Autodesk Inventor Professional 2017. Variabel beban AC outdoor yang diterima oleh masing-masing dudukan AC yaitu 156,96; 176,58; 196,2, dan 215,82 N. Hasil simulasi menunjukkan untuk berat AC Outdoor 156,96; 176,58; 196,2, dan 215,82 N memiliki faktor keamanan berturut-turut yaitu 2,559; 2,275; 2,047, dan 1,861.
\end{abstract}

Kata kunci: metode elemen hingga, dudukan ac, autodesk inventor 2017, analisis tegangan, aluminium 5052

\section{ABSTRACT}

This study examined the design and analysis of the strength of the outdoor AC bracket using the finite elemen method. The analysis is done using Autodesk Inventor Professional 2017 software. Variable of the outdoor AC load by each AC bracket were 156,96 N; 176,58 N; 196,2 N, and 215,82 N. The simulation results show that for the outdoor AC loads of 156,96 N;176,58 N; $196,2 \mathrm{~N}$, and 215,82 $\mathrm{N}$, the safety factors are 2,559; 2,275; 2,047, and 1,861, respectively.

Keywords: finite element method, ac bracket, autodesk inventor 2017, stress analysis, aluminium 5052

\section{PENDAHULUAN}

Kandungan asam yang tinggi di pesisir pantai menimbulkan banyak kerugian yang disebabkan oleh tingginya laju korosi. Laju korosi yang tinggi berdampak pada berkurangnya umur pakai dari sebuah komponen. Komponen-komponen yang terbuat dari material logam khususnya besi dan baja adalah material yang paling dominan terkena dampaknya.

Balai Uji Teknologi dan Pengamatan Antariksa dan Atmosfer atau Balai LAPAN Garut adalah sebuah balai tempat melaksanakan uji teknologi penerbangan dan antariksa, khususnya uji statik dan uji terbang roket, serta uji pesawat LSU (LAPAN Surveillance UAV). Balai LAPAN Garut berada di pesisir Pantai Cilauteureun sehingga membuat lingkungan Balai LAPAN Garut sangat tinggi dengan bahaya korosi.

Banyaknya ruangan di Balai LAPAN Garut yang menggunakan Air Conditioner (AC) menimbulkan banyak masalah terutama pada komponen Dudukan AC outdoor. Mayoritas Dudukan AC outdoor yang terbuat dari logam baja (mild steel) mengalami korosi sehingga mengurangi kekuatan dan umur pakai dari komponen tersebut.

Penelitian ini bertujuan merancang Dudukan (bracket) AC outdoor dengan material Aluminium paduan seri 5052 yang merupakan material yang sering digunakan di tempat-tempat dengan tingkat korosi yang tinggi. Material tersebut juga memiliki kekuatan luluh (yield strength) yang cukup tinggi yaitu sebesar $193 \mathrm{MPa}$ [1]. Nilai kekuatan luluh tersebut cukup digunakan untuk mengangkat beban dari AC outdoor dengan kapasitas pendinginan yang cukup besar. 


\section{METODOLOGI PENELITIAN}

\subsection{Material}

Material yang digunakan untuk Dudukan AC yaitu material Aluminium paduan 5052. Komposisi kimia standar material Aluminium 5052 dapat dilihat pada Tabel 1.

Tabel 1. Komposisi Kimia Standar Material Al 5052 menurut ASTM [2]

\begin{tabular}{cccccccc}
\hline Material & $\mathrm{Si}$ & Iron & Copper & $\mathrm{Mn}$ & $\mathrm{Mg}$ & $\mathrm{Cr}$ & Zinc \\
\hline $\mathrm{Al} 5052$ & 0,25 & 0,40 & 0,10 & 0,10 & $2,20-2,80$ & $0,15-0,35$ & 0,10 \\
\hline
\end{tabular}

Aluminium 5052 memiliki banyak kelebihan, antara lain kemampuan kerja yang baik, kekuatan statis sedang, kekuatan lelah yang tinggi, kemampuan las yang baik, dan ketahanan korosi yang sangat baik, terutama di daerah laut [3].

\subsection{Perangkat lunak (Software)}

Penelitian ini menggunakan perangkat lunak (software) Autodesk Inventor Professional 2017 untuk membuat gambar 1 Dimensi (3D) dan melakukan pengujian kekuatan Dudukan AC outdoor.

Autodesk Inventor adalah salah satu perangkat lunak (software) jenis Computer Aided Drawing (CAD) yang lebih menekankan pada pemodelan solid. Autodesk Inventor Professional adalah salah satu produk dari Autodesk Inc. USA yang dulu lebih familier dengan produk AutoCAD [4]. Analisis tegangan yang dilakukan oleh Autodesk Inventor menggunakan metode analisis elemen hingga sehingga kita dapat menganalisis desain yang sesuai dengan keinginan [5]. Analisis elemen hingga adalah teknik numerik matematis untuk menghitung kekuatan dan perilaku struktur komponen teknik dengan membagi obyek menjadi bentuk jala (mesh).

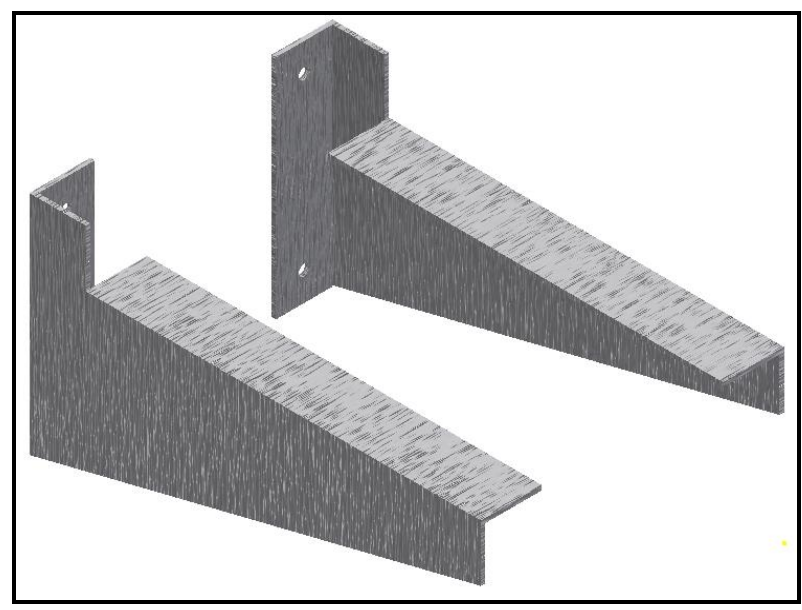

Gambar 1. Desain 3D Dudukan AC Outdoor

Prosedur menjalankan simulasi tegangan menggunakan software Autodesk Inventor Professional 2017 ada beberapa tahapan:

Pertama, mendesain rangka Dudukan AC. Desain meliputi bentuk dan dimensi dari Dudukan AC. Bahan yang digunakan adalah plat dengan tebal $4 \mathrm{~mm}$. Dimensi secara detail ditunjukkan pada Gambar 2.

Kedua, menentukan jenis material yang digunakan. Material yang dipilih adalah Aluminium 5052 yang merupakan material yang tahan korosi. 
Ketiga, menentukan batasan (constraint). Batasan yang digunakan adalah fixed constraint pada 2 (dua) lubang baut.

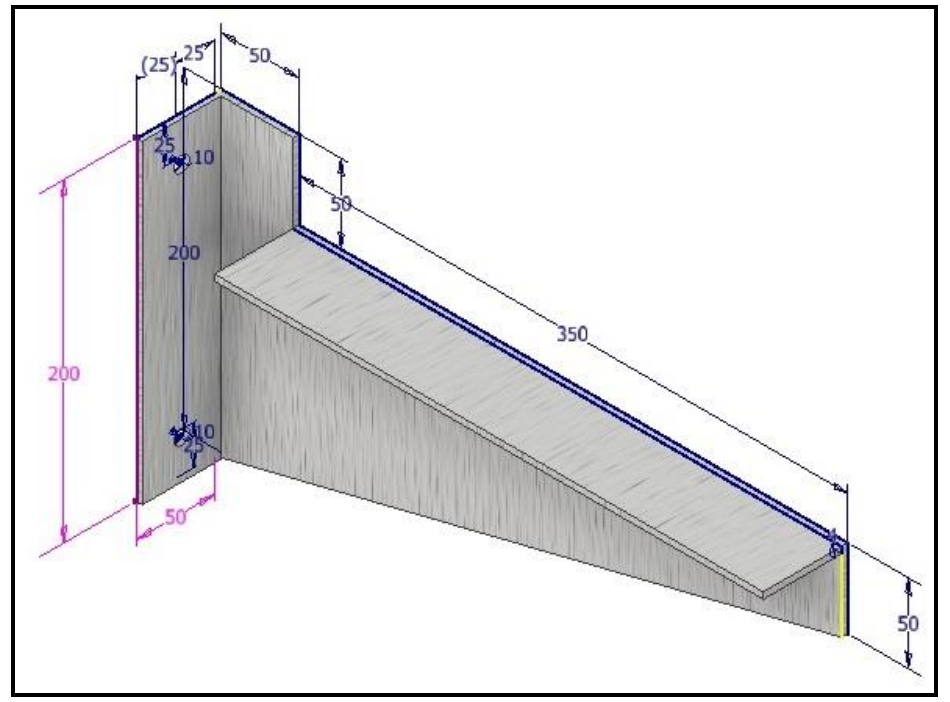

Gambar 2. Dimensi Dudukan AC Outdoor (dalam mm)

Keempat, menentukan besarnya beban. Beban yang digunakan adalah $16 \mathrm{~kg}, 18 \mathrm{~kg}, 20 \mathrm{~kg}$, dan $22 \mathrm{~kg}$. Beban dinyatakan dalam satuan Newton (N) dengan mengalikannya dengan percepatan gravitasi $\left(9,81 \mathrm{~m} / \mathrm{s}^{2}\right)$. Beban berturut-turut menjadi 156,96 N; 176,58 N; 196,2 N; dan 215,82 N.

Kelima, menjalankan proses meshing. Proses meshing material pada simulasi ini membagi material menjadi 2324 node dan 1065 elemen seperti ditunjukkan pada Gambar 3.

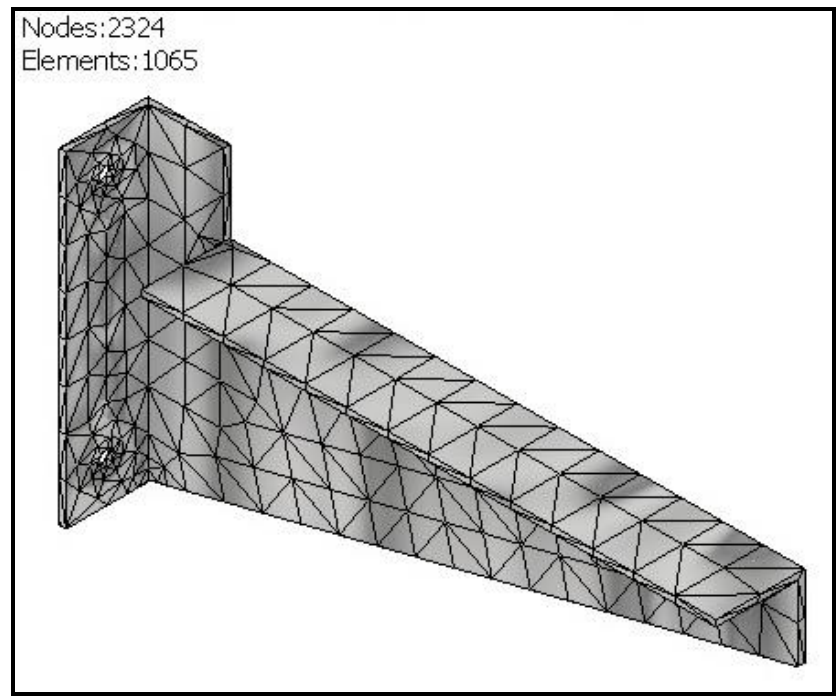

Gambar 3. Proses Meshing Dudukan AC Outdoor

Keenam, menjalankan simulasi program. Simulasi program akan menghasilkan tegangan Von Mises, deformasi (displacement), dan safety factor. Simulasi program juga akan menampilkan titik-titik kritis dari desain yang telah kita buat. 
Parameter Analisis Tegangan menggunakan Autodesk Inventor Professional 2017 secara lengkap dapat dilihat dari Tabel 2 berikut ini.

Tabel 2. Parameter Analisis Tegangan

\begin{tabular}{ll}
\hline Tipe Simulasi & Single Point \\
\hline Variabel berat AC Outdoor & $16 \mathrm{~kg}, 18 \mathrm{~kg}, 20 \mathrm{~kg}$, dan $22 \mathrm{~kg}$ \\
\hline Percepatan gravitasi & $9,81 \mathrm{~m} / \mathrm{s}^{2}$ \\
\hline Total muatan & $156,96 \mathrm{~N} ; 176,58 \mathrm{~N} ; 196,2 \mathrm{~N}$, dan $215,82 \mathrm{~N}$ \\
\hline Average element size & $0,1 \mathrm{~mm}$ \\
\hline Minimum element size & $0,2 \mathrm{~mm}$ \\
\hline Safety Factor & Berdasarkan yield strength \\
\hline Jumlah node & 2324 \\
\hline Jumlah elemen & 1065 \\
\hline
\end{tabular}

\section{HASIL DAN PEMBAHASAN}

\subsection{Analisis Sifat Fisik Material}

Tabel 3. menunjukkan sifat fisik material Aluminium paduan 5052. Material Aluminium 5052 memiliki densitas sebesar 2,68 gram $/ \mathrm{cm}^{3}$. Hal ini berdampak pada massa total Dudukan AC yang cukup ringan, yaitu hanya seberat $0,749 \mathrm{~kg}$.

Tabel 3. Sifat fisik material Dudukan AC Outdoor [1]

\begin{tabular}{ll}
\hline \multicolumn{1}{c}{ Parameter } & Keterangan \\
\hline Material & Aluminum 5052 \\
\hline Density & $2,68 \mathrm{~g} / \mathrm{cm}^{3}$ \\
\hline Mass & $0,749 \mathrm{~kg}$ \\
\hline Area & $145190 \mathrm{~mm}^{2}$ \\
\hline Volume & $279372 \mathrm{~mm}^{3}$ \\
\hline Yield Strength & $193 \mathrm{MPa}$ \\
\hline Ultimate Tensile Strength & $228 \mathrm{MPa}$ \\
\hline Young's Modulus & $70,3 \mathrm{GPa}$ \\
\hline Poisson's Ratio & $0,33 \mathrm{ul}$ \\
\hline Shear Modulus & $26,43 \mathrm{GPa}$ \\
\hline
\end{tabular}

\subsection{Analisis Tegangan Von Mises, Deformasi, dan Safety Factor}

Gambar 3, Gambar 4, dan Gambar 5 menunjukkan hasil simulasi Dudukan AC outdoor terhadap beban 215,82 N. Tegangan Von Mises maksimal sebesar 103,699 N. Tegangan Von Mises masih berada di bawah kekuatan luluh (yield strength) material Aluminium 5052, yaitu sebesar $193 \mathrm{MPa}$. Nilai deformasi maksimal juga relatif kecil, yaitu 1,626 mm. Safety factor minimum yaitu 1,861 . Nilai ini berada di bawah standar yang dipersyaratkan untuk suatu komponen mampu 
menahan beban dinamis. Nilai safety factor yang dipersyaratkan untuk suatu komponen mampu menahan beban dinamis yaitu pada kisaran angka 2-3 [6]. Hal ini karena Dudukan AC outdoor selalu mengalami beban getaran (vibration) terus-menerus dari kompresor saat AC sedang bekerja.

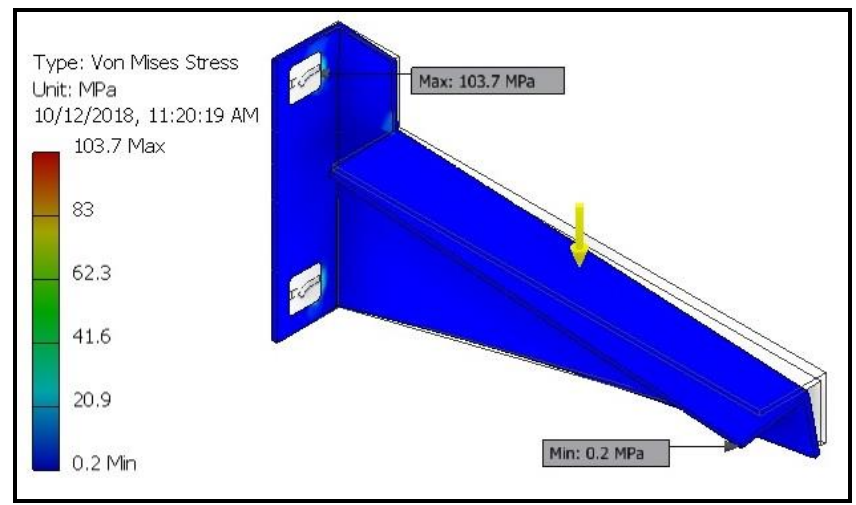

Gambar 4. Tegangan Von Mises Dudukan AC outdoor dengan beban 215,82 N.

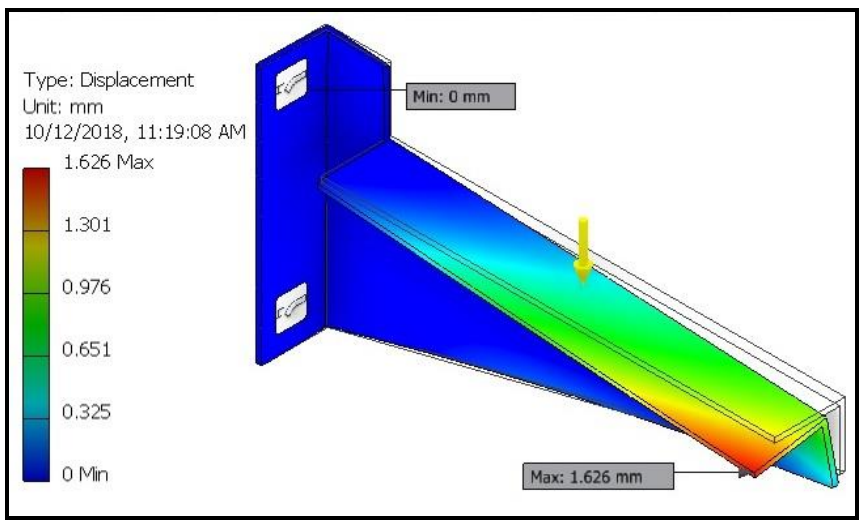

Gambar 5. Deformasi Dudukan AC outdoor dengan beban 215,82 N.

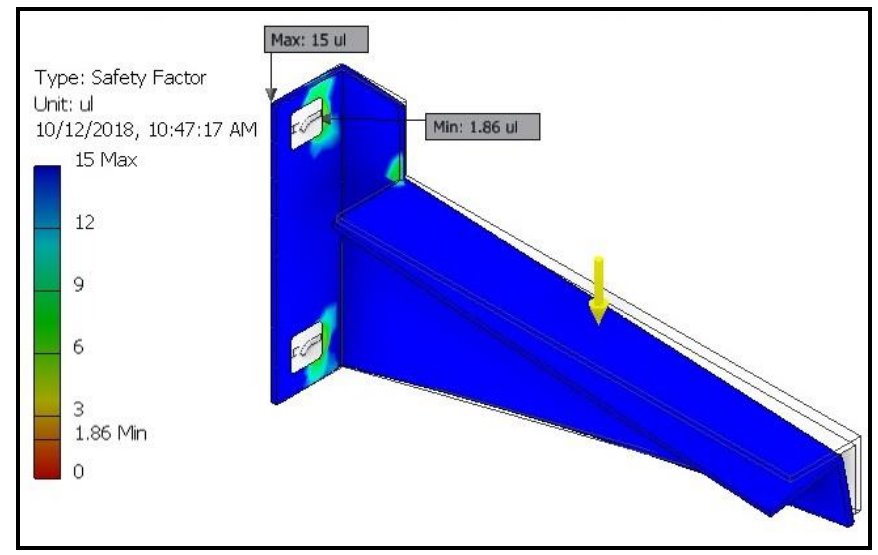

Gambar 6. Faktor keamanan Dudukan AC outdoor dengan beban 215,82 N. 
Hasil simulasi Dudukan AC outdoor secara lengkap dapat dilihat pada Tabel 3. Hasil simulasi menunjukkan rancangan Dudukan AC outdoor masih cukup aman untuk menahan beban 196,2 N. Hal ini karena nilai safety factor sebesar 2,047. Sehingga, untuk 1 (satu) pasang Dudukan AC outdoor mampu menahan beban AC outdoor sebesar 392,4 $\mathrm{N}$ atau berat sekitar $40 \mathrm{~kg}$.

Tabel 3. Hasil simulasi Dudukan AC Outdoor

\begin{tabular}{llcccc}
\hline \multirow{2}{*}{ Hasil Simulasi } & & \multicolumn{4}{c}{ Beban AC Outdoor } \\
\cline { 3 - 6 } & & $\mathbf{1 5 6 , 9 6} \mathbf{~ N}$ & $\mathbf{1 7 6 , 5 8} \mathbf{~ N}$ & $\mathbf{1 9 6 , 2} \mathbf{~ N}$ & $\mathbf{2 1 5 , 8 2 ~ \mathbf { ~ }}$ \\
\hline Von Mises Stress $(\mathbf{M P a})$ & Minimum & 0,159 & 0,178 & 0,198 & 0,218 \\
\hline & Maksimum & 75,421 & 84,847 & 94,272 & 103,699 \\
\hline Deformasi $(\mathbf{m m})$ & Minimum & 0 & 0 & 0 & 0 \\
\hline & Maksimum & 1,183 & 1,330 & 1,478 & 1,626 \\
\hline Safety Factor & Minimum & 2,559 & 2,275 & 2,047 & 1,861 \\
\hline & Maksimum & 15 & 15 & 15 & 15 \\
\hline
\end{tabular}

\section{KESIMPULAN}

1. Desain Dudukan AC outdoor menggunakan material Aluminium 5052 memiliki massa yang yang cukup ringan, yaitu sebesar $0,749 \mathrm{~kg}$.

2. Dudukan AC outdoor masih cukup aman untuk menahan beban hingga 196,2 N. Hal ini karena nilai faktor keamanannya sebesar 2,047.

3. Untuk 1 (satu) pasang Dudukan AC outdoor berarti mampu untuk menahan beban AC outdoor hingga sebesar 392,4 $\mathrm{N}$ atau berat sekitar $40 \mathrm{~kg}$.

\section{DAFTAR PUSTAKA} 2018. Autodesk Material Library. United States: Autodesk Inc.

[2] ASTM B 209. 1996. Standards Specification for Aluminum and Aluminum - Alloy Sheet and Plate. United States: ASTM International.

[3] Raveendra, Kumar Ravi, Sivakumar A, and Santosh N. 2014. "Effect Of Welding Parameters On 5052 Aluminium Alloy Weldments Using TIG Welding”. International Journal of Innovative Research In Science, Engineering And Technology. 3.3, 10302-10309.

[4] Wibawa, Lasinta Ari Nendra. 2018. Merancang Komponen Roket 3D dengan Autodesk Inventor Professional 2017. Surakarta: Buku Katta.

[5] Wibawa, Lasinta Ari Nendra. 2018. Simulasi Kekuatan Komponen Sarana Pengujian Roket Menggunakan Autodesk Inventor Professional 2017. Surakarta: Buku Katta.

[6] Dobrovolsky V. 1978. Machine Elements. Moscow: Peace Publisher. 